\title{
Field-aligned currents observed by CHAMP during the intense 2003 geomagnetic storm events
}

\author{
H. Wang ${ }^{1,2}$, H. Lühr ${ }^{2}$, S. Y. Ma ${ }^{1}$, J. Weygand ${ }^{3}$, R. M. Skoug ${ }^{4}$, and F. Yin ${ }^{1,2}$ \\ ${ }^{1}$ Dept. of Space Physics, College of Electronic Information, Wuhan University, P. R. China \\ ${ }^{2}$ GeoForschungsZentrum, Potsdam, Germany \\ ${ }^{3}$ Institute of Geophysics and Planetary Physics, University of California, Los Angeles, USA \\ ${ }^{4}$ Los Alamos National Laboratory, Los Alamos, New Mexico, USA
}

Received: 22 June 2005 - Revised: 24 October 2005 - Accepted: 14 December 2005 - Published: 7 March 2006

\begin{abstract}
This study concentrates on the characteristics of field-aligned currents (FACs) in both hemispheres during the extreme storms in October and November 2003. Highresolution CHAMP magnetic data reflect the dynamics of FACs during these geomagnetic storms, which are different from normal periods. The peak intensity and most equatorward location of FACs in response to the storm phases are examined separately for both hemispheres, as well as for the dayside and nightside. The corresponding large-scale FAC peak densities are, on average, enhanced by about a factor of 5 compared to the quiet-time FACs' strengths. And the FAC densities on the dayside are, on average, 2.5 times larger in the Southern (summer) than in the Northern (winter) Hemisphere, while the observed intensities on the nightside are comparable between the two hemispheres. Solar wind dynamic pressure is correlated with the FACs strength on the dayside. However, the latitudinal variations of the FACs are compared with the variations in $D_{s t}$ and the interplanetary magnetic field component $B_{z}$, in order to determine how these parameters control the large-scale FACs' configuration in the polar region. We have determined that (1) the equatorward shift of FACs on the dayside is directly controlled by the southward IMF $B_{z}$ and there is a saturation of the latitudinal displacement for large value of negative $B_{z}$. In the winter hemisphere this saturation occurs at higher latitudes than in the summer hemisphere. (2) The equatorward expansion of the nightside FACs is delayed with respect to the solar wind input. The poleward recovery of FACs on the nightside is slower than on the dayside. The latitudinal variations on the nightside are better described by the variations of the $D_{s t}$ index. (3) The latitudinal width of the FAC region on the nightside spreads over a wide range of about $25^{\circ}$ in latitude.
\end{abstract}

Keywords. Ionosphere (Auroral ionosphere) - Magnetospheric Physics (Current systems; Magnetosphere/ionosphere interactions)

Correspondence to: $\mathrm{H}$. Wang

(h.wang@whu.edu.cn)

\section{Introduction}

A geomagnetic storm typically lasts from one to three days and encompasses the entire magnetosphere. The $D_{s t}$ index is used to assess the strength of a geomagnetic storm. Traditionally, this index is derived from an average deflection of the geomagnetic field horizontal component measured at four low-latitude stations. Usually the magnetic storm can be divided into three phases: the Storm Sudden Commencement (SSC) (a positive deflection of $D_{s t}$ associated with a sudden increase in solar wind dynamic pressure), the main phase characterized by a decrease in $D_{s t}\left(d D_{S T} / d t<0\right)$ and the recovery phase $\left(d D_{s t} / d t>0\right)$ (Maltsev, 2004).

The solar wind is expected to influence the distribution and characteristics of field-aligned currents (FACs) (e.g. Wang et al., 2005). A number of solar wind coupling parameters are put forward, which include a selected combination of quantities, such as the Interplanetary Magnetic Field (IMF), solar wind velocity $\left(v_{s w}\right)$, clock angle $(\theta)$, the angle of the IMF in the GSM $y-z$ plane with respect to the $+\mathrm{z}$ direction and dynamic pressure $\left(P_{d}\right)$. For example, Akasofu's coupling parameter, $\varepsilon=1 / \mu_{0} v_{s w}\left(B_{x}^{2}+B_{y}^{2}+B_{z}^{2}\right) \sin ^{4}(\theta / 2) l_{0}^{2}$, can serve as an indicator for the energy input during intense geomagnetic storms (Akasofu, 1979), where $B_{x}, B_{y}$, $B_{z}$ are components of IMF and $l_{0}$ is a constant scale length, $\simeq 7$ Earth radii. Troshichev and Lukianova (1996) concluded that the merging electric field, $E_{m}=v_{s w} \sqrt{B_{y}^{2}+B_{z}^{2}} \sin ^{2}(\theta / 2)$, is a suitable geoeffective solar wind coupling parameter for loading the magnetosphere. Bythrow (1984) determined that the boundaries of the auroral FACs shifted equatorward (poleward) during periods of southward (northward) IMF. The rate of the equatorward expansion is related to $P_{d}$, where the greater the pressure, the faster the equatorial expansion (Anderson et al., 2002). Furthermore, Anderson et al. (2002) found that the intensification and equatorward expansion of the global FACs occurred in response to a southward IMF $B_{z}$ and the strongest FACs occurred during the most intense negative $B_{z}$ (corresponding to the storm main phase) and the 
weakest FACs occurred during northward IMF. The study of Anderson et al. (2002) was based on two storms, 2223 September 1999 , with a minimum $D_{s t}$ of approximately $-160 \mathrm{nT}$, and 21-22 October 1999, with a minimum $D_{s t}$ of $-230 \mathrm{nT}$. Iijima and Potemra (1978) found that very intense cusp currents seemed to be associated with the southward IMF $B_{z}$ component. However, some intense FACs also occurred in the cusp region during periods of large positive $B_{z}$. Furthermore, the strong IMF $B_{y}$ component can also yield an intensification of significant FACs, but does not affect the FAC equatorward shift (e.g. Friis-Christensen and Wilhjelm, 1975; Anderson et al., 2002). In our study, the abovementioned parameters along with the $D_{s t}$ index will be used together to characterize the storm-related inputs during the two events we have examined.

One of the most obvious responses of the auroral region to the enhanced solar wind input during a geomagnetic storm is the equatorward expansion of the auroral oval. The positions of the midnight and the noon sectors of the auroral oval shift in response to the variations of the IMF southward component, but they do not necessarily move with the $D_{s t}$ intensity variations (Meng, 1984).

The latitudinal position of the dayside auroral oval varies during geomagnetic storms with the IMF $B_{z}$ component while the nightside auroral oval is less sensitive to IMF $B_{z}$ (Burch, 1979). Meng (1984) has examined the latitudinal variation of the noon and nightside auroral oval during three intense storms with the $D_{s t}$ minima values of $-156 \mathrm{nT}$, $-120 \mathrm{nT}$ and $-150 \mathrm{nT}$. He found that the noon sector aurora was displaced by a few degrees more than the nightside region near the peak of the magnetic storm, and the midnight auroral oval recovered more slowly than the noon sector during the storm recovery phase. Furthermore, the equatorial boundary of the nightside auroral oval was shown to expand below $50^{\circ}$ during extremely intense storms. Associated with the equatorward shift of the auroral oval is the expansion of the polar cap. This can be regarded as an indication of the buildup of the open magnetic flux in the magnetotail (Milan et al., 2004).

On the dayside FACs are closely related to the magnetopause reconnection process (Ma et al., 1995), which is also associated with the creation of new open flux. Nightside FACs, embedded in the auroral oval, are intimately related to both the tail current and the ring current (Mauk and Zanetti, 1987). Therefore, we expect that the solar wind will have a different effect on the dayside and nightside FACs' intensities and locations during intense storms.

Fujii et al. (1992) were the first to report on the dynamic variations of FACs in the northern morning (07:00-10:00 MLT) and southern evening sectors (19:00-21:00 MLT) during the great magnetic storm on 13-14 March 1989, as recorded by the EXOS D satellite. They determined that the latitudinal width of the FAC region increased during the storm, particularly in the morning sector, where it covered about $33^{\circ}$ in latitude. In the evening sector during the storm the FAC distribution developed into complicated patterns consisting of many pairs of upward and downward FAC sheets. In addition, Christiansen and Papitashvili (2003) found that the averaged region 1 (R1) FACs saturated during the storm main phase. Siscoe et al. (2002) hypothesized that the magnetic field of the R1 FACs reduced the field strength at the magnetopause, thereby preventing further increase in the R1 FACs.

With the Iridium satellite constellation Anderson et al. (2002) determined that there were differences in the decreasing FAC magnitude and in the velocity of the poleward retreat of the FACs for different geomagnetic storm recovery phases. During a rapid $D_{s t}$ recovery, the storm current intensity decreased to prestorm levels within an hour and was accompanied by a prompt poleward retreat, while a more gradual $D_{s t}$ recovery corresponded to the gradual poleward retreat and sustained strong FACs above quiet levels. In addition, they reported similar global FAC intensifications and time developments in the autumn (Northern) and spring (Southern) Hemispheres.

The ionospheric conductivity is also expected to affect the FACs' location and intensity (e.g. Fujii et al., 1981; Wang et al., 2005). The dependences of FAC intensity and location in the dayside and the nightside on ionospheric conductivity during quiet periods have been statistically studied (e.g. Fujii et al., 1981; Wang et al., 2005). It was found that the intensity of FACs changed with the solar radiation-induced conductivity only on the dayside, not on the nightside. On the dayside a systematic difference of the footprint latitude between sunlit and dark conditions emerged with a $2^{\circ}$ equatorward retreat under dark conditions. Over large parts of the night sector there was no influence on the average position of the currents. One of the questions we will address in this study is whether the solar radiation-induced ionospheric conductivity also plays a role for the dayside and nightside FACs during extreme storm periods. In this study we will compare the FACs' features in the winter (Northern) and summer (Southern) Hemispheres during the October and November 2003 storms.

This work includes: (1) a report on the high resolution CHAMP observations of the dayside and nightside FAC density and position during the 29-31 October, and 20-22 November 2003 storms; (2) an investigation of the variation of the noon and midnight FACs in association with solar wind parameters, IMF $B_{x}, B_{y}, B_{z}, v_{s w}, P_{d}, E_{m}$ and $\varepsilon$; and (3) a comparison of the storm-time dynamics of the dayside and nightside FACs in the summer and winter hemispheres. In the following section we describe the instrumentation and data processing. The event analysis of the observations is presented in Sect. 3. In Sect. 4 the results are discussed in the context of previous publications. Section 5 summarizes the conclusions drawn from the observations.

\section{Instrumentation and data processing}

The geoscientific satellite CHAMP was launched on 15 July 2000 from the Russian cosmodrome Plesetsk into a circular, near-polar orbit (87.3 inclination) (Reigber et al., 2002). At 
the beginning of the mission the altitude was $456 \mathrm{~km}$, decaying to $350 \mathrm{~km}$ after 5 years. CHAMP has delivered a unique data set. The instrument of prime interest for this study is the Fluxgate Magnetometer (FGM), which delivers vector field readings at a rate of $50 \mathrm{~Hz}$ with a resolution of $0.1 \mathrm{nT}$. The data are calibrated routinely with respect to the onboard absolute scalar Overhauser Magnetometer. A dual-head star camera system, mounted together with the FGM on an optical bench, provides the orientation of the measured field vectors with arcsecond precision. Data used in this study are the $1-\mathrm{Hz}$ calibrated (Level 2) vector data in the North-EastCenter (NEC) frame which are available publicly through the CHAMP data center, ISDC (product identifier: $\mathrm{CH}-\mathrm{ME}-2-$ FGM-NEC).

The FAC density, $j_{z}$, is determined according to Ampère's law from the magnetic field data by solving the curl-B, that is, $j_{z}=\frac{1}{\mu_{0}}\left(\frac{\partial B_{y}}{\partial x}-\frac{\partial B_{x}}{\partial y}\right)$, where $\mu_{o}$ is the vacuum permeability, $B_{x}$ and $B_{y}$ are the transverse magnetic field components caused by the currents. We have used the same approach as described in Wang et al. (2005) to obtain the FAC denstity. Since we do not have multi-point measurements, we convert observed temporal variations into spatial gradients by considering the velocity under the assumption of the stationarity of the current during the time of satellite passage. After discrete sampling is introduced (Lühr et al., 1996), we obtain $j_{z}=\frac{1}{\mu_{0} v_{x}} \frac{\Delta B_{y}}{\Delta t}$, where $v_{x}$ is the velocity perpendicular to the current sheet and $B_{y}$ is the magnetic deflection component parallel to the sheet.

We have assumed that the FACs are organized in infinite sheets that are aligned with the mean location of the auroral oval. Evidences for such geometry have been examined previously (e.g. Iijima and Potemra, 1976; Sugiura and Potemra, 1976; Zanetti et al., 1983). During a magnetic storm these conditions may not apply. However, Lühr et al. (1996) have shown that any deviation (oblique crossing or finite extent of sheet) can lead to a factor of 2 underestimation of the current density. For this study, the absolute value of the current density is not crucial. The latitude of peak current density is, however, not significantly affected by the uncertainty in the current geometry and can be regarded as reliable. The current estimates are given in corrected magnetic coordinates (i.e. magnetic latitudes (MLAT) and local times (MLT)), which are calculated from the Apex algorithms described by Richmond (1995). Averages of FAC densities are binned in a grid of $1^{\circ}$ MLAT. The same latitudes are revisited by CHAMP satellite after $93 \mathrm{~min}$ of the orbital period.

The solar wind parameters used in this study are measured by the ACE satellite. The solar wind data have been propagated from the ACE satellite to the magnetopause with the minimum variance method outlined in Weimer et al. (2003). ACE solar wind plasma data are accessible through the ACE Science Center Web site, however, reliable solar wind density data could not be provided by the SWEPAM instrument for the October storms for two reasons. The first is that the solar wind tracking algorithm failed under high radiation background levels associated with the intense solar energetic particle event. The second reason is that the peak in the energy spectrum of the solar wind beam exceeded the search mode energy range and thus could not be tracked properly (Skoug et al., 2004). To fill these gaps we have used data from a different instrument mode, the so-called search mode, which gives, however, only one reading every $33 \mathrm{~min}$. These data and their limitations were previously presented in Skoug et al. (2004).

\section{Events study}

The events we will examine occurred on 29-31 October and 20-22 November 2003. The first results of these Sun-Earth connection events have been summarized by Gopalswamy et al. (2005a). The $D_{s t}$ index was $-180 \mathrm{nT},-363 \mathrm{nT},-401 \mathrm{nT}$, and $-472 \mathrm{nT}$ for all 4 storms and all the storms were driven by Coronal Mass Ejections (CME) observed in the solar wind (Gopalswamy et al., 2005b). During the times of interest, the CHAMP satellite was approximately in the noon-midnight meridian (13:00 01:00 MLT sector for October events and 11:00 23:00 MLT for November event), thus enabling us to study the dayside and nightside dependence of large-scale FACs on solar wind parameters and storm effects. An interhemispheric comparison enables us to also investigate the seasonal differences of the FACs.

\subsection{Storms of 29-31 October 2003}

A succession of intense magnetic storms occurred on 29-31 October 2003 and were accompanied by extreme geophysical conditions. Figure 1 shows the time history of 8 quantities related to the magnetic activity. Shown in the figure are $72 \mathrm{~h}$ of one-hour averages of the data, beginning on 29 October 2003 at 00:00 UT. We will refer to the individual hours as Storm Time (ST). The left column of Fig. 1 contains the components of the IMF $B_{x}, B_{y}, B_{z}$ in GSM coordinates and the $D_{s t}$ index. In the right column we can see $v_{s w}, P_{d}, E_{m}$ and $\varepsilon$

We use the $D_{s t}$ index to indicate the three storm intervals, where the first occurs with a minimum of $-180 \mathrm{nT}$ at 10:00 ST, the second with a minimum of $-363 \mathrm{nT}$ at 25:00 ST, and the third with a minimum of $-401 \mathrm{nT}$ at 47:00 ST. Between each storm there is some recovery of the $D_{s t}$ index. We refer to these three periods as the first, the second and the third storm time in the following, in Yizengaw et al. (2005).

The peak values of the energy input, as defined by $\varepsilon$, are about $0.5,4,3.5 \times 10^{13} \mathrm{~J} / \mathrm{s}$, for the first, second and third storm times, respectively. At about the same time $E_{m}$ peaks attain values of about 20,26 and $40 \mathrm{mV} / \mathrm{m}$, respectively. $v_{s w}$ exceeds $1800 \mathrm{~km} / \mathrm{s}$ twice around 06:00 and 44:00 ST. Unfortunately, due to the poor proton density data, $P_{d}$, for the first two storms, could not be reliably determined (Skoug et al., 2004). Despite the relatively small $D_{s t}$ value during the first storm, the corresponding $K_{p}$ and $A E$ indices are quite large. The geomagnetic activity index, $K_{p}$, reaches 

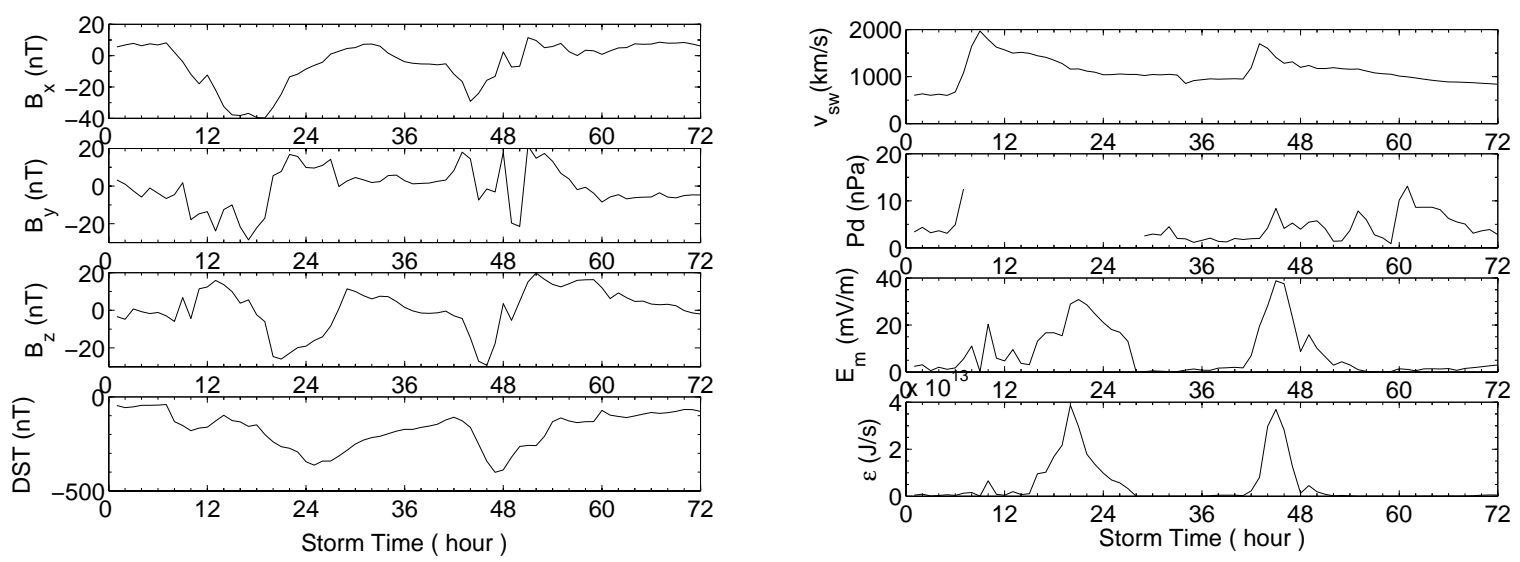

Fig. 1. Typical storm-time solar wind parameters, including IMF $B_{x}, B_{y}, B_{z}$ components in GSM coordinate system, velocity, $v_{s} w$, dynamic pressure, $P_{d}$, merging electric field, $E_{m}$, Akasofu parameter, $\varepsilon$, and $D_{s t}$ variations on 29-31 October 2003.
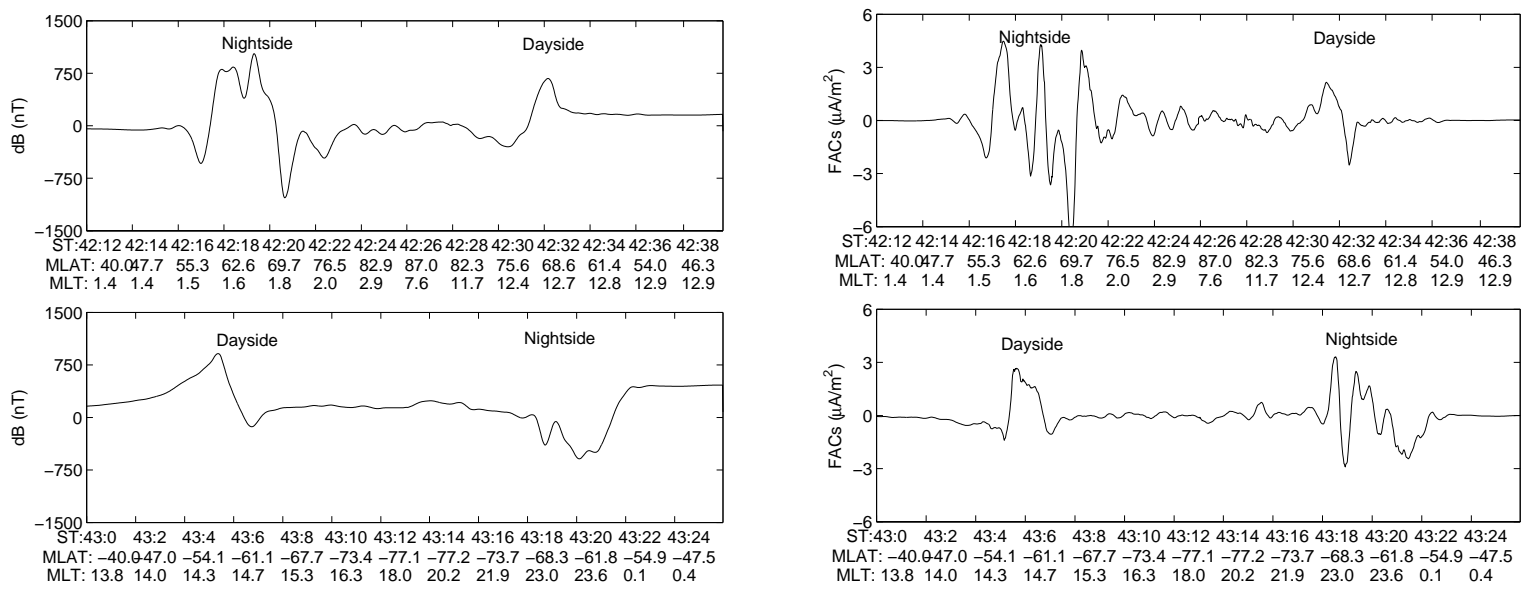

Fig. 2. Examples of the storm-time magnetic measurements and derived FACs for individual CHAMP passes over the north and south poles.

9o, 9- and 9o during the three storm intervals from 06:00 to 09:00 ST, 18:00 to 27:00 ST and 42:00 to 48:00 ST, respectively. The auroral electrojet index, $A E$, is determined to be $2250 \mathrm{nT}, 2000 \mathrm{nT}$ and $1750 \mathrm{nT}$ in the three intervals of 07:00-12:00 ST, 13:00-27:00 ST and 36:00-52:00 ST (both indices are not shown in Fig. 1; see Liu and Lühr (2005) for more information).

For the first storm, an SSC is observed at 06:11 ST on 29 October 2003. The main phase for this storm takes place between 07:00 ST and 10:00 ST and occurs just after a southward turning of the IMF at $\sim 06: 00 \mathrm{ST}$ that reaches a minimum of $-10 \mathrm{nT}$. After the main phase $B_{z}$ is only moderately southward or even northward. The recovery phase begins after the IMF $B_{z}$ turns northward. $B_{x}$ and $B_{y}$ become more negative during the whole period of the first storm.

The second storm main phase occurs between 14:00 ST and 26:00 ST and is associated with a strong southward $B_{z}$ of about $-28 \mathrm{nT}$ around 20:00 ST. The recovery phase begins $5 \mathrm{~h}$ after the IMF $B_{z}$ turns northward at 20:00 ST. $B_{x}$ and $B_{y}$ turn from negative to positive around 15:00 and 17:00 ST.

The third storm main phase is observed between 42:00 ST and 47:00 ST, during which the IMF $B_{z}$ decreases to $-33 \mathrm{nT}$ at around 45:00 ST. The recovery phase of this event begins about 1 hour after the IMF $B_{z}$ turns northward. During this storm $P_{d}$ stays below $7 \mathrm{nPa}, B_{x}$ turns from negative to positive around 44:00 ST and $B_{y}$ fluctuates between 20 and $-20 \mathrm{nT}$ at 42:00 ST and 52:00 ST, respectively.

The main phases of these three events are all accompanied by a southward IMF $B_{z}$ and the recovery phases of all events are accompanied by the northward turning of IMF $B_{z}$, which is consistent with the previous studies that believe storms are strongly related to the southward IMF periods (e.g. Gonzalez and Tsurutani, 1987; Maltsev, 2004).

Figure 2 shows, as an example, the variations of the relevant magnetic component $d B_{y}$ (left) and the derived fieldaligned current density (right), for an individual CHAMP pass over the north and south poles on 30 October 2003. Negative (positive) currents denote downward (upward) FACs 

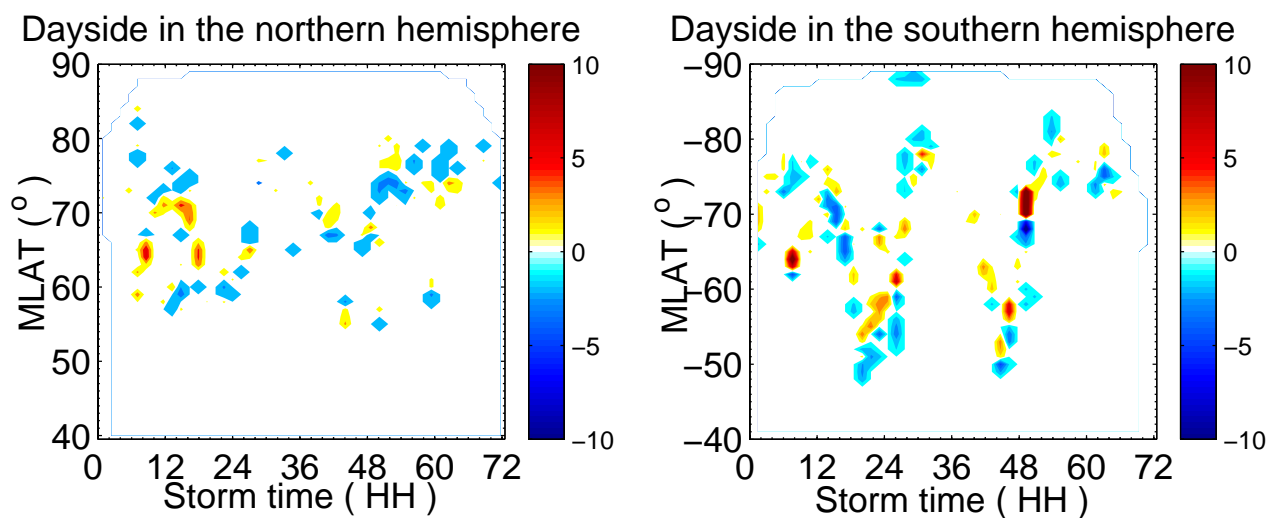

Nightside in the northern hemisphere
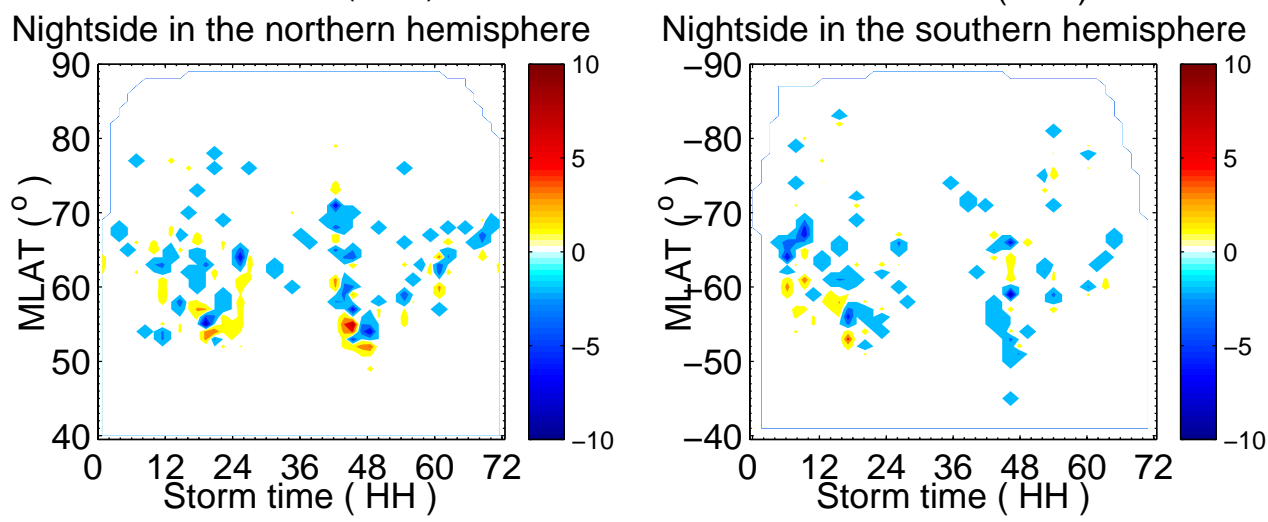

Fig. 3. Storm-time FACs observed by CHAMP in the daytime (top) and nighttime (bottom) sectors on 29-31 October 2003 in the Northern (left) and Southern(right) Hemispheres. Current densities are given in $\mu \mathrm{A} / \mathrm{m}^{2}$.
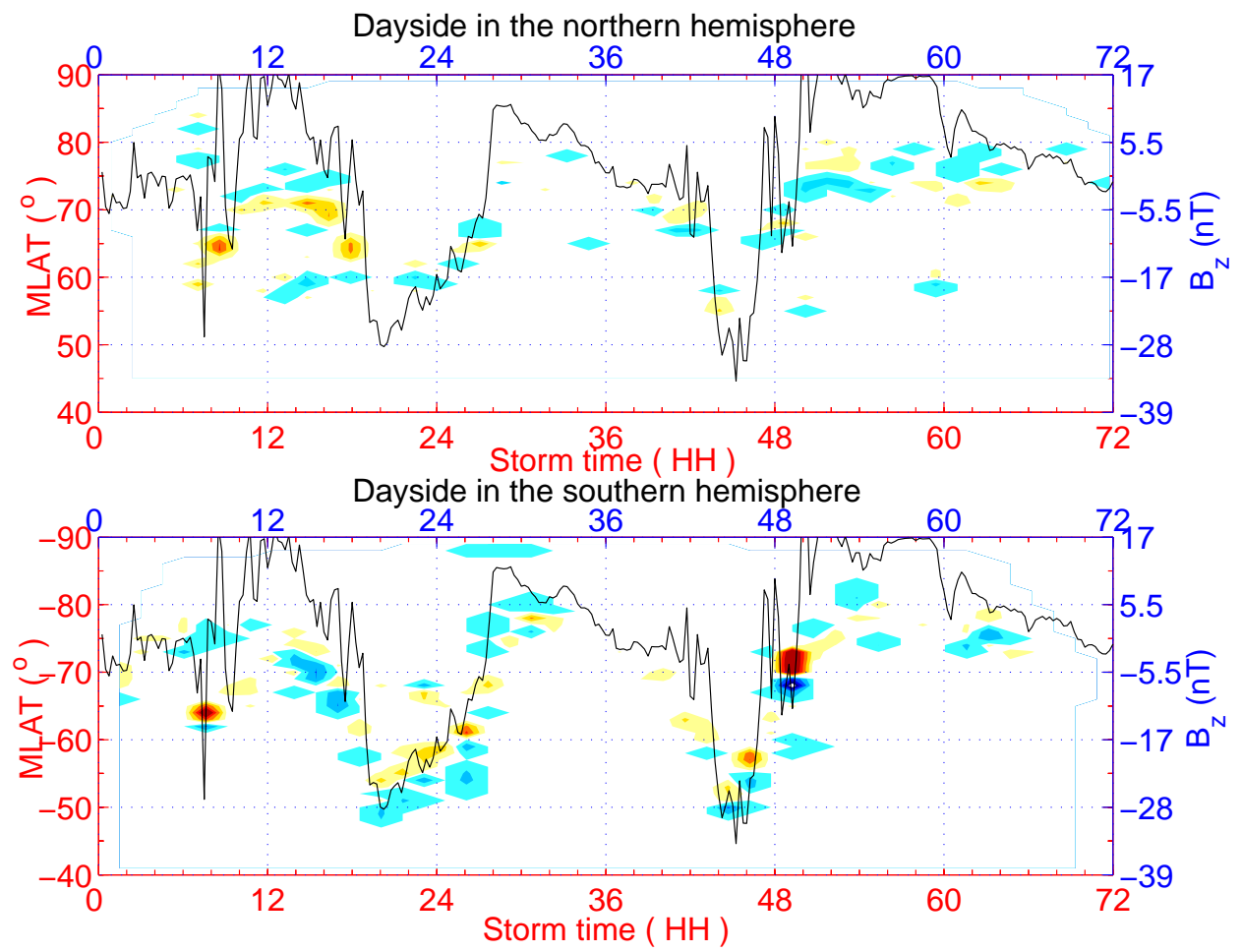

Fig. 4. Latitudinal variation of FACs occurrence on the dayside in comparison with the IMF $B_{z}$ amplitude in both hemispheres for the October event. 


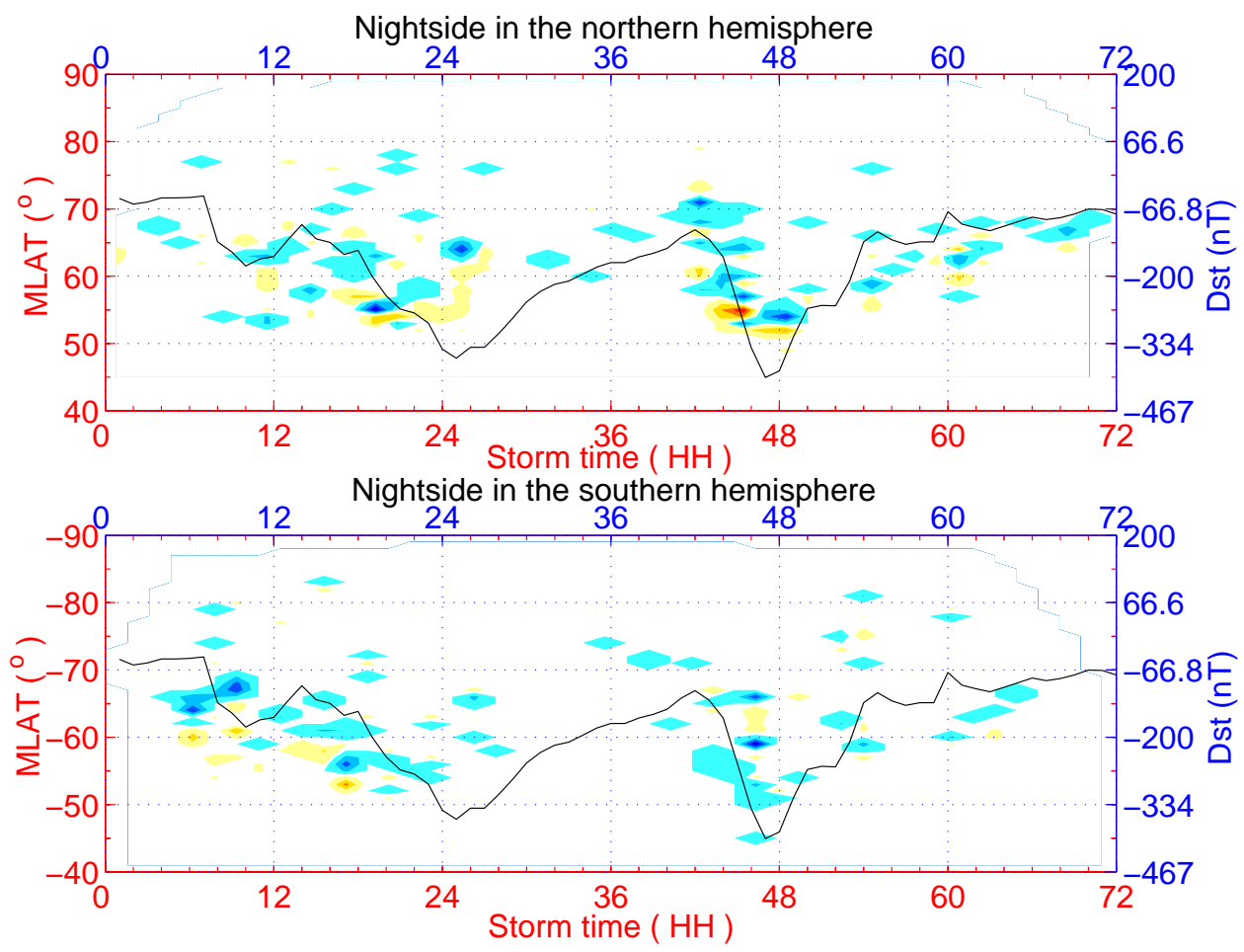

Fig. 5. Latitudinal variation of the FACs occurrence on the nightside in comparison with the $D_{s t}$ value in both hemispheres for the October event.

flowing into (out of) the ionosphere. A well-defined FAC sheet can be found on the dayside in both hemispheres, while there are multiple FAC sheets on the nightside covering a wide range of latitudes (about $21^{\circ}$ ).

Figure 3 shows the color-coded distribution of FAC density as a function of MLAT versus ST, as observed by the CHAMP satellite. Separate frames are used for the dayside and nightside in both hemispheres. In the figure we display only FAC densities with magnitudes greater than $1 \mu \mathrm{A} / \mathrm{m}^{2}$, which are typical during nominal periods (Wang et al., 2005), and smaller magnitudes are omitted, in order to focus on the intense FACs.

Figure 3 demonstrates that the temporal variation of the magnetic latitude of the intense FACs is well correlated with the three storm periods. This behavior is more obvious on the dayside than on the nightside, where the most poleward FACs are not well correlated with the storm phases, while the most equatorward FACs are better correlated. As a result, the total latitudinal range of FACs can, at times, be much wider than the normal width. This is especially true during the most active periods of the storm. For example, at 16:00 ST the equatorward boundary of the FACs on the nightside in the Southern Hemisphere shifts to $57^{\circ}$ MLAT, but the poleward boundary stays around $82^{\circ}$ MLAT, resulting in a total range of $25^{\circ}$ in magnetic latitude. Fujii et al. (1992) already noticed a disagreement between the response of the poleward and the equatorward FACs to the storm-time activity. The response of the equatorward FACs is found to roughly correlate with the IMF $B_{z}, D_{s t}, E_{m}$ and $\varepsilon$ during extreme activity. All these parameters however, do, not peak at the same time. For example, in our events, minima in $D_{s t}$ occurred 1 to $2 \mathrm{~h}$ later than minima in $B_{z}$.

It is well-known that for enhanced geomagnetic activity the auroral oval expands equatorward. Here we want to test whether the southward IMF or $D_{s t}$ index can be used to predict the equatorward latitudes of the FACs. Figure 4 has the same format as Fig. 3, except that 15-min averages of IMF $B_{z}$ are shown. This figure demonstrates that the latitudinal variation of the FACs on the dayside follows IMF $B_{z}$ rather closely. The best correlation appears to be between the Southern Hemisphere FACs and negative IMF $B_{z}$. In the Northern Hemisphere we find some significant discrepancies between the time of the $B_{z}$ minima and the minimum equatorward latitudes of FACs on the dayside, as well as localized FAC peaks at 35:00 ST, 49:00 ST, and 59:00 ST. The minimum equatorward latitudes of FACs on the dayside occur at 07:00 ST $\left(57^{\circ}\right), 22: 00 \mathrm{ST}\left(56^{\circ}\right)$, and 44:00 ST $\left(54^{\circ}\right)$ in the Northern Hemisphere and at 08:00 ST $\left(-61^{\circ}\right), 20: 00$ ST $\left(-47^{\circ}\right)$, and 45:00 ST $\left(-48^{\circ}\right)$ in the Southern Hemisphere. These times match almost the three phases when the $B_{z}$ minima occur, but not to the three phases when $D_{s t}$ minima occur, around 10:00, 25:00 and 47:00 ST.

In Fig. 5 we compare the latitudinal variation of the FAC distribution on the nightside with the variation of $D_{s t}$. Figure 5 indicates that the motion of the equatorward border of the intense FACs on the nightside correlates with $D_{s t}$ 

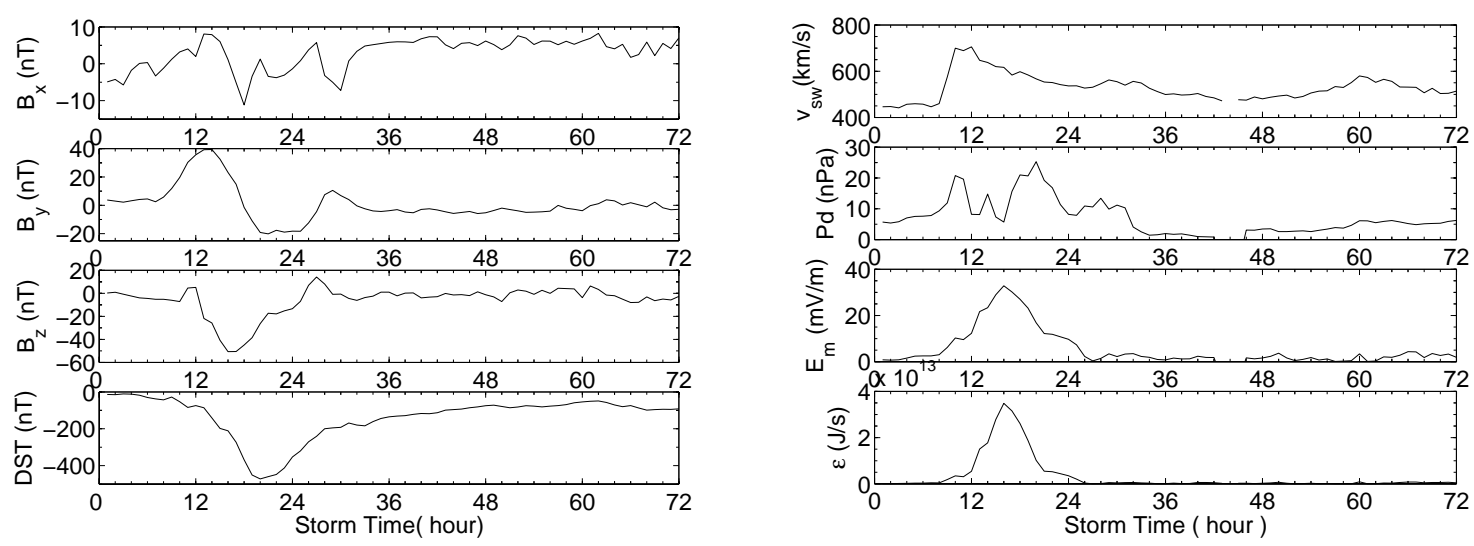

Fig. 6. Typical storm-time solar wind parameters, including IMF $B_{x}, B_{y}, B_{z}$ components in the GSM coordinate system, velocity, $v_{s w}$, dynamic pressure, $P_{d}$, merging electric field, $E_{m}$, Akasofu parameter, $\varepsilon$, and $D_{s t}$ variations on 20-22 November 2003.

reasonably well, while the dayside motion does not correlate as well with $D_{s t}$. After IMF $B_{z}$ turns northward the latitudinal motion of the dayside FACs is slower than the nightside.

The minimum equatorward latitudes of FACs on the nightside occur at 12:00 ST $\left(53^{\circ}\right), 25: 00 \mathrm{ST}\left(52^{\circ}\right)$, and 47:00 ST $\left(50^{\circ}\right)$ in the Northern and 10:00 ST $\left(-54^{\circ}\right), 21: 00 \mathrm{ST}\left(-51^{\circ}\right)$, and 47:00 ST $\left(-46^{\circ}\right)$ in the Southern Hemisphere. Most of these latitudinal minima are further equatorward than the dayside minima. This is as expected since the auroral oval on the nightside is normally located at lower magnetic latitudes than on the dayside. However, the times at which the midnight FACs reached their minimum latitudes occur almost 1$3 \mathrm{~h}$ later than those in the noontime sector.

Figures 4 and 5 also show that peak FAC intensities do not coincide with the most equatorward FACs, minima in $D_{s t}$, or minima in $B_{z}$. For example, during the first storm event (between 06:00 and 14:00 ST), in the Northern Hemisphere on the dayside (upper frame in Fig. 3), the FAC peaks around 09:00 ST with an amplitude of $\sim 5 \mu \mathrm{A} / \mathrm{m}^{2}$. These upward FACs are located at $\sim 64^{\circ}$.

Figure 4, which displays the dayside FACs, demonstrates that the magnitudes of the peak FACs in the Southern Hemisphere are larger than those in the Northern Hemisphere. This is not the case for the nightside FACs. The peak FACs in Fig. 5 on the nightside in the Northern Hemisphere are sometimes larger or comparable to those in the Southern Hemisphere. However, we should recall that the CHAMP spacecraft samples each polar region only once every $93 \mathrm{~min}$ and may have missed several larger events.

\subsection{The November storm event}

The isolated geomagnetic storm on 20 November 2003 is the most intense storm of those examined in this study. The observations of this storm will be presented in the same format as the October storms. Figure 6 shows the hourly averaged solar wind parameters and $D_{s t}$ variations for the November storm. The SSC occurs at 08:03 ST on 20 November
2003 and $D_{s t}$ decreases to the minimum value of $-472 \mathrm{nT}$ at 20:00 ST. Following the minimum, the recovery phase begins with the slow increase of $D_{s t}$ until it reaches a nearly constant value of about $100 \mathrm{nT}$, where it remains for another $24 \mathrm{~h}$. During the main phase of the storm between 12:00 and 19:00 ST, the IMF $B_{z}$ decreased to $-60 \mathrm{nT}$ at about 17:00 ST and then begins to increase. Around the time of the $B_{z}$ minimum the IMF $B_{y}$ switches sign. This reversal of the IMF $B_{y}$ component at the minimum of $B_{z}$ is consistent with the passage of the CME-related flux rope.

The upper right panel of Fig. 6 shows that $v_{s w}$ jumps from about $450 \mathrm{~km} / \mathrm{s}$ to $700 \mathrm{~km} / \mathrm{s}$ before 09:00 ST, which is the cause of the SSC. Following this sharp increase, $v_{s w}$ recovers to pre-storm levels within $36 \mathrm{~h}$. During the storm, $P_{d}$ peaks at about $20 \mathrm{nPa}$ and $35 \mathrm{nPa}$ around 10:00 ST and 20:00 ST, respectively. The two lower right panels indicate that $E_{m}$ and the solar wind magnetosphere energy input, $\varepsilon$, peak at about 16:00 ST during the main phase of the storm. $E_{m}$ reaches a value of about $32 \mathrm{mV} / \mathrm{m}$ and at about the same time $\varepsilon$ peaks at $3.5 \times 10^{13} \mathrm{~J} / \mathrm{s}$ and remains greater than $1 \times 10^{13} \mathrm{~J} / \mathrm{s}$ for about $8 \mathrm{~h}$. Not shown here are $K_{p}$ and the auroral electrojet index. $K_{p}$ obtains a maximum of about 9- between 16:00-21:00 ST and $A E$ reaches values greater than $1750 \mathrm{nT}$ at about 14:00 ST.

Figure 7 demonstrates the equatorward motion of the FAC sheets during the November magnetic storm. The latitudinal motion of the FACs is clearer on the dayside in the top two panels than on the nightside in the bottom two panels. The dayside FACs reach a minimum latitude of $57^{\circ}\left(-53^{\circ}\right)$ at about 18:00 ST (17:00 ST) in the Northern (Southern) Hemisphere, which correspond to the minimum IMF $B_{z}$, around 17:00 ST (see Fig. 6). Figure 8 demonstrates both the equatorward shift of the FACs with the decrease in the IMF $B_{z}$ (here 15-min averages are used), and the subsequent poleward shift of the FACs with the increase in the IMF $B_{z}$. We find that the latitudinal motion of the FACs is clearer during this storm than the October events, especially for the observations made in the Southern Hemisphere. Again, we find 
Dayside in the northern hemisphere

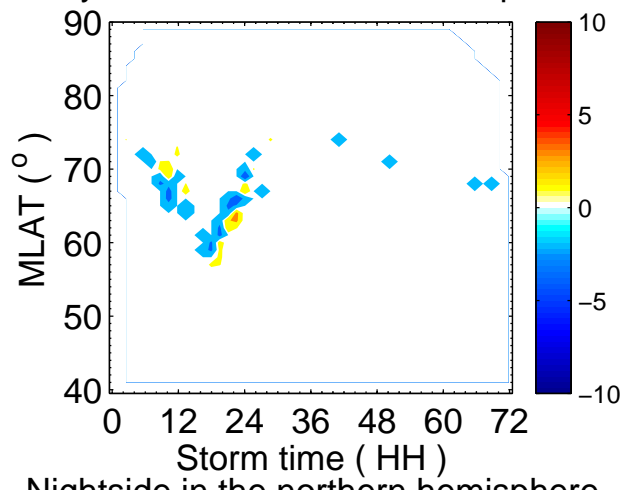

Nightside in the northern hemisphere

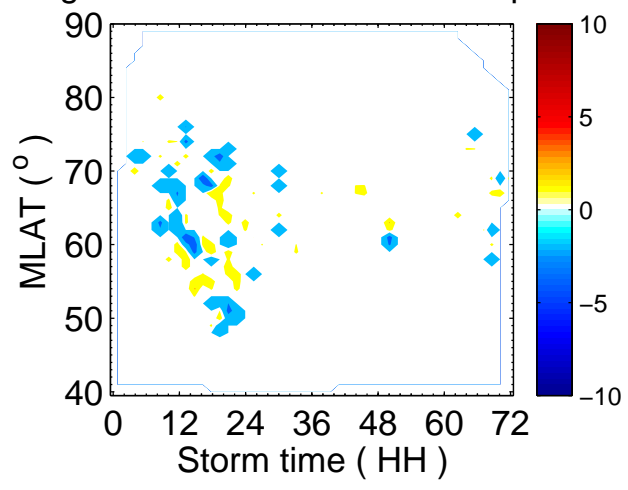

Dayside in the southern hemisphere

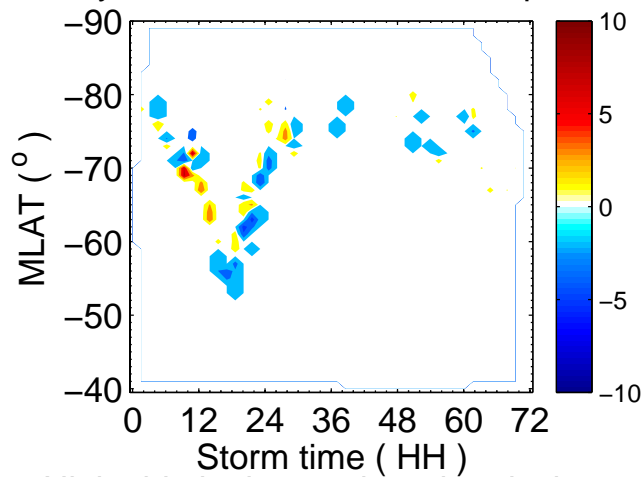

Nightside in the southern hemisphere

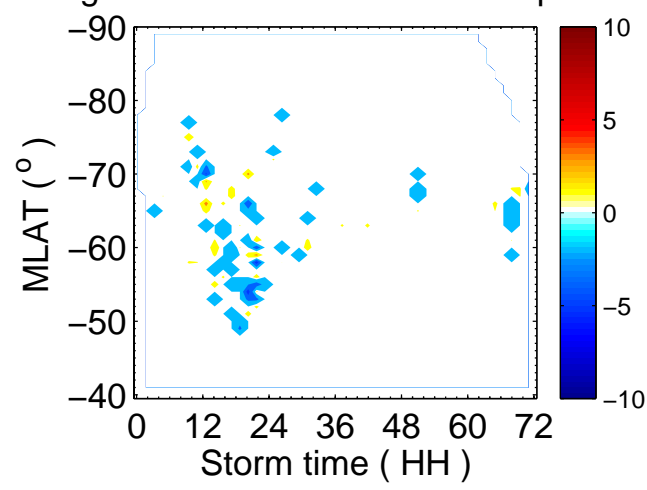

Fig. 7. Storm-time FACs observed by CHAMP in the daytime (top) and nighttime (bottom) sectors on 20-22 November 2003 in the Northern (left) and Southern (right) Hemispheres. Current densities are given in $\mu \mathrm{A} / \mathrm{m}^{2}$.
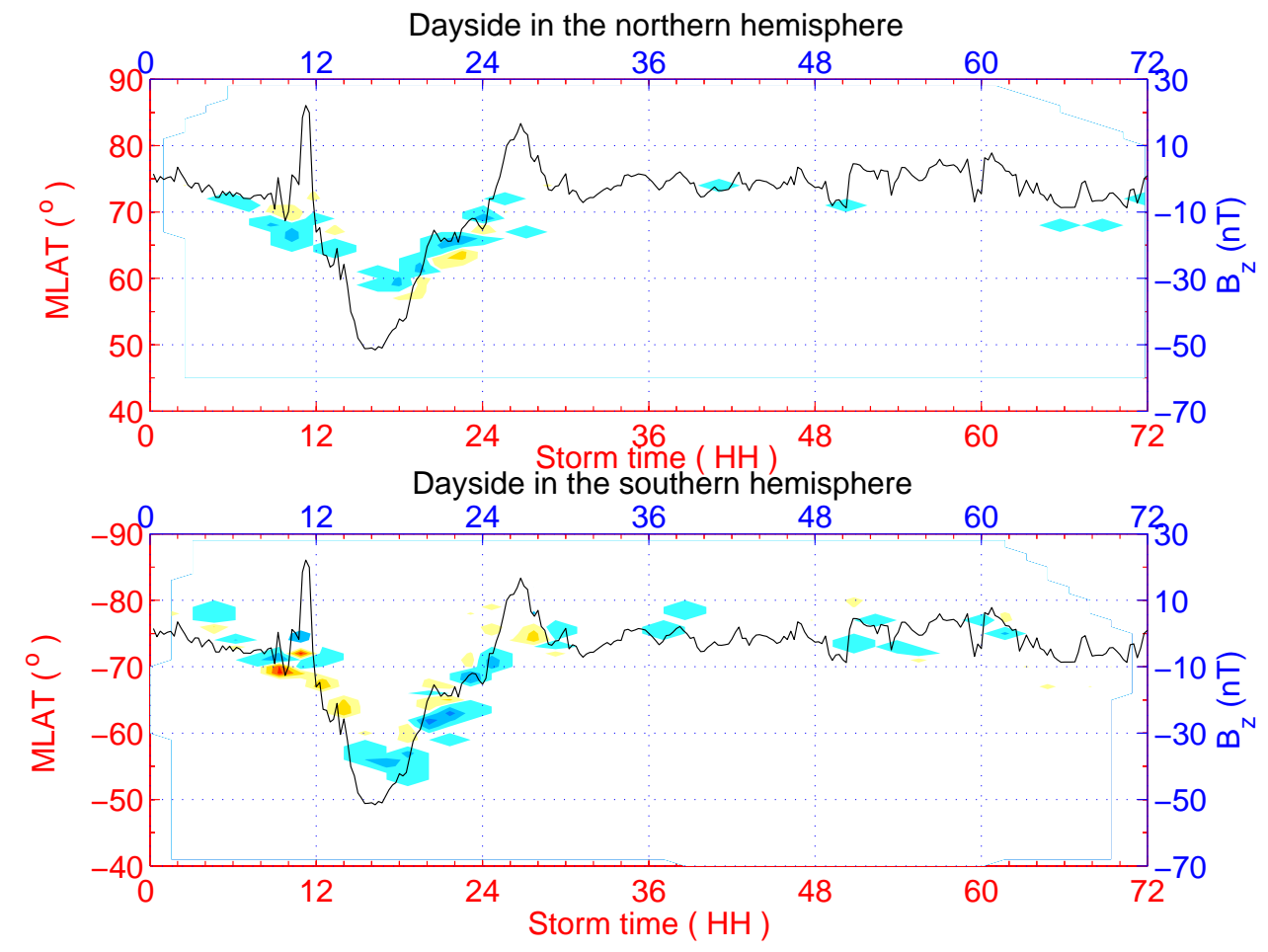

Fig. 8. Same as Fig. 4 but for November event. 


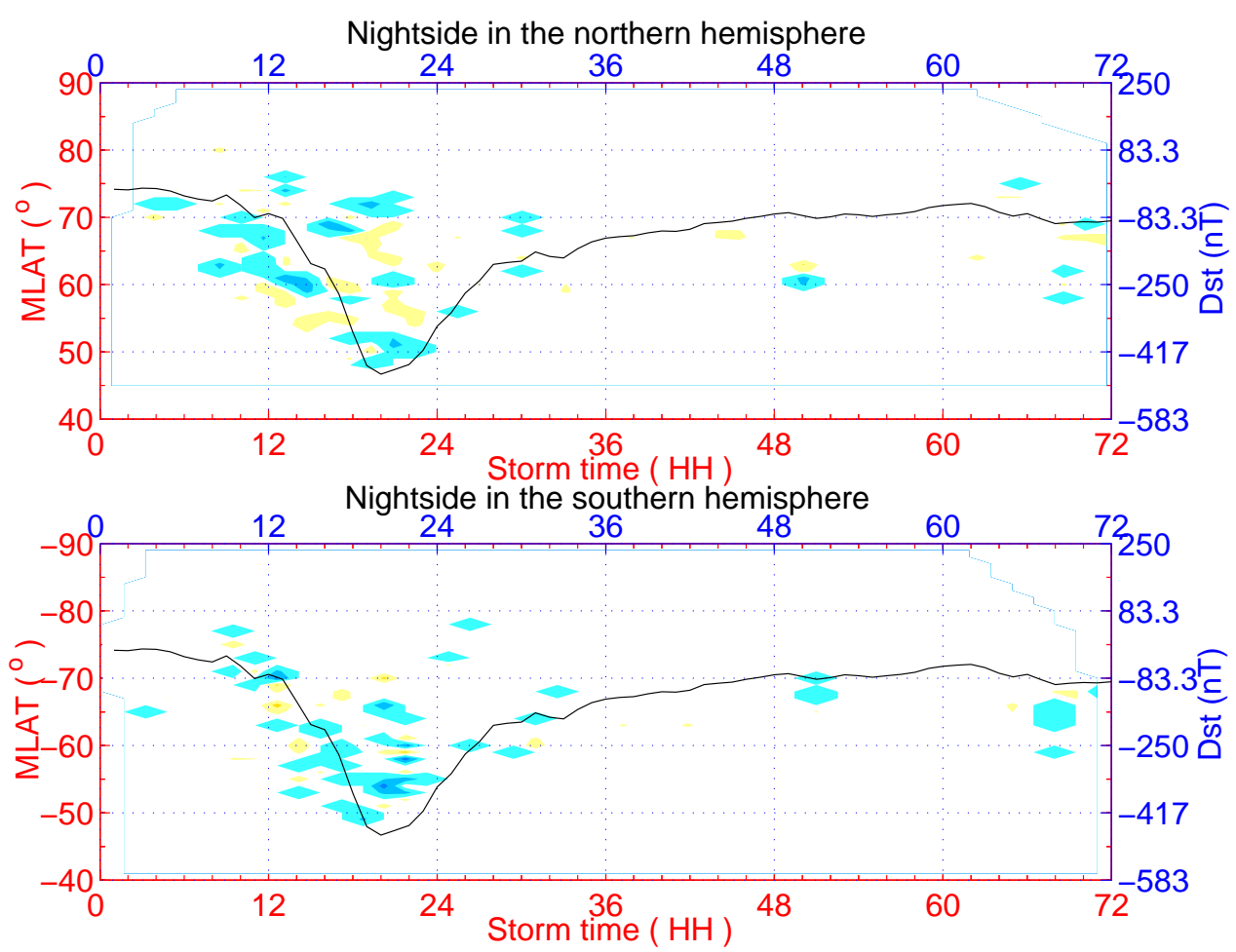

Fig. 9. Same as Fig. 5 but for November event.

Table 1. The peak density of FACs at the dayside and nightside in the Northern (Southern) Hemispheres for the October (event 1-1 3) and November (event 2) event.

\begin{tabular}{|c|c|c|c|c|c|c|c|c|c|c|c|c|}
\hline & \multicolumn{6}{|c|}{ north } & \multicolumn{6}{|c|}{ south } \\
\hline & \multicolumn{3}{|c|}{ day } & \multicolumn{3}{|c|}{ night } & \multicolumn{3}{|c|}{ day } & \multicolumn{3}{|c|}{ night } \\
\hline & $\mathrm{ST}(\mathrm{HH})$ & $\operatorname{MLAT}\left({ }^{\circ}\right)$ & $\mathrm{j}\left(\mu \mathrm{A} / \mathrm{m}^{2}\right)$ & $\mathrm{ST}(\mathrm{HH})$ & $\operatorname{MLAT}\left({ }^{\circ}\right)$ & $\mathrm{j}\left(\mu \mathrm{A} / \mathrm{m}^{2}\right)$ & $\mathrm{ST}(\mathrm{HH})$ & $\operatorname{MLAT}\left({ }^{\circ}\right)$ & $\mathrm{j}\left(\mu \mathrm{A} / \mathrm{m}^{2}\right)$ & $\mathrm{ST}(\mathrm{HH})$ & $\operatorname{MLAT}\left({ }^{\circ}\right)$ & $\mathrm{j}\left(\mu \mathrm{A} / \mathrm{m}^{2}\right)$ \\
\hline event $1-1$ & 09:00 & 64 & 5 & 11:00 & 53 & -4 & 08:00 & -63 & 14 & 08:00 & -66 & -6 \\
\hline event $1-2$ & 17:00 & 64 & 6 & 20:00 & 56 & -9 & 26:00 & -61 & 9 & 15:00 & -53 & 6 \\
\hline event $1-3$ & $52: 00$ & 73 & -4 & $46: 00$ & 52 & 10 & 50:00 & -70 & 15 & $46: 00$ & -59 & -10 \\
\hline event 2 & 23:00 & 69 & -4.2 & $16: 00$ & 69 & -4.5 & 11:00 & -69 & 8.5 & 22:00 & -58 & -10 \\
\hline
\end{tabular}

systematic deficits of the observed FAC latitude compared to the one predicted by IMF $B_{z}$ around the minimum of $B_{z}$. The difference is larger in the Northern Hemisphere.

Figure 8 also shows that during the decreasing phase of the IMF $B_{z}$ the most equatorward FACs point downward in the Northern and upward in the Southern Hemisphere. The opposite relation is observed during the increasing phase of $B_{z}$. The difference in the FAC configuration between the two hemispheres is consistent with the polarity of the large IMF $B_{y}$.

Figure 9 presents the latitude distribution of the intense FACs on the nightside. It has the same format as Fig. 8 but compares the latitudinal shift of the FACs with the variation of $D_{s t}$. Here again, the equatorward boudnary of the FACs decreases in latitude with the decrease in $D_{s t}$. When we compare the latitudinal spread of the FACs in Fig. 8 with those in
Fig. 9 we see that the spread is wider on the nightside than on the dayside. Figure 9 also shows that the nightside FACs reach a latitude of $47^{\circ}\left(-49^{\circ}\right)$ in the Northern (Southern) Hemisphere at 19:00 ST (20:00 ST). The maximum equatorward expansion occurs $2 \mathrm{~h}$ later on the nightside than the maximum equatorward expansion on the dayside.

The last item we see in Figs. 8 and 9 is that the peak intensities of the FACs do not coincide with the most equatorward location of the FACs, the minimum $D_{s t}$, or the minimum $B_{z}$ (cf. Fig. 7). On the dayside in the Northern Hemisphere the strongest FACs of $\sim-4.2 \mu \mathrm{A} / \mathrm{m}^{2}$ is located at $\sim 69^{\circ}$ MLAT at about 23:00 ST. On the dayside in the Southern Hemisphere the largest FACs has a peak density of about $8.5 \mu \mathrm{A} / \mathrm{m}^{2}$, located at $-69^{\circ}$ MLAT at about 11:00 ST. A detailed summary of the peak FACs sorted by events is given in Table 1. The table gives the storm time, MLAT, and value of the largest 

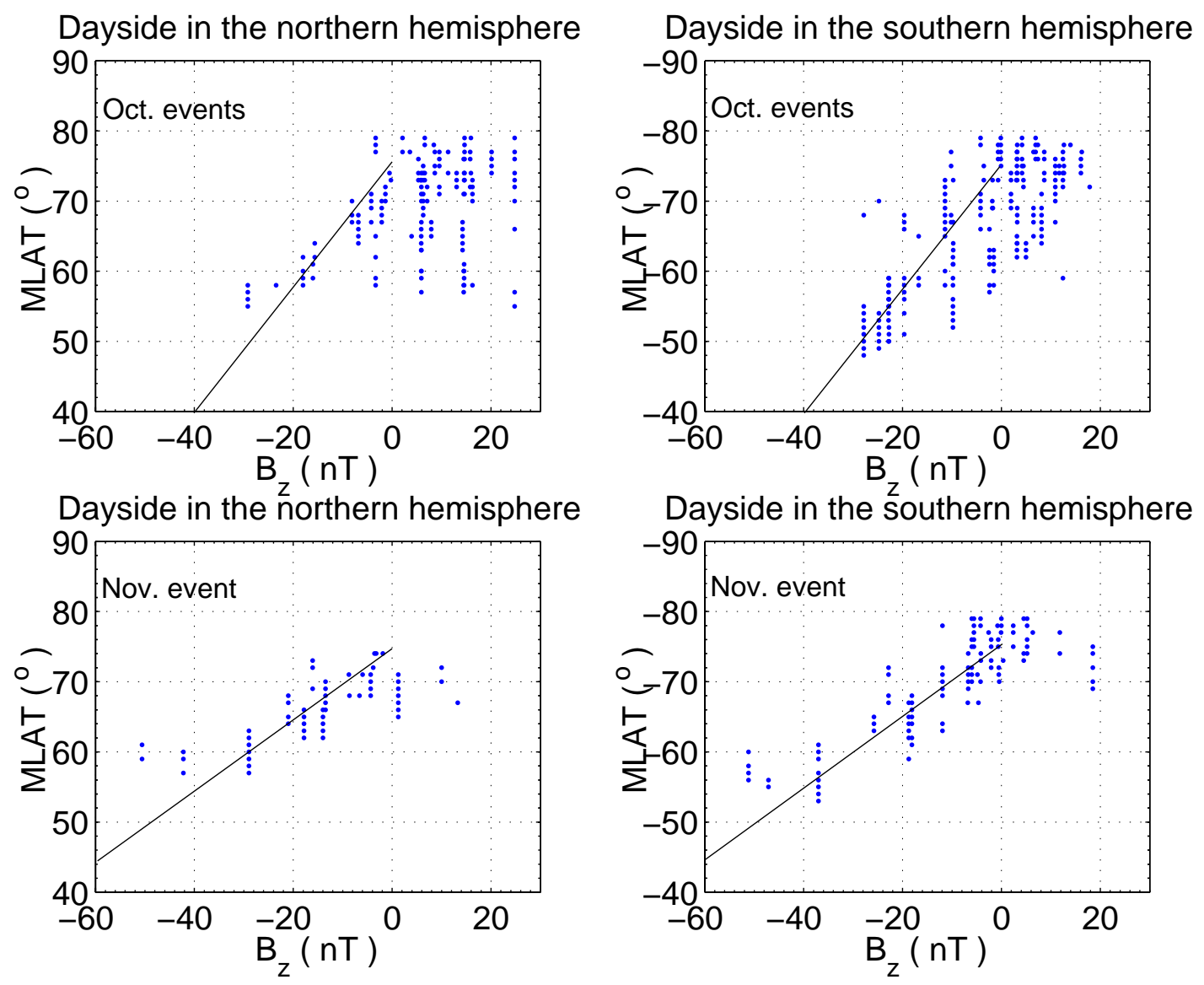

Fig. 10. Scatter plots of the latitudes versus $B_{z}$ for intense FACs density of the October and November events. The black lines represent the scaling between southward IMF $B z$ and MLAT of FACs used in Figs. 4 and 8.

FAC density for both the dayside and nightside in both the Northern and Southern Hemispheres. In the next section we will discuss the similarities and the differences of FAC characteristics for all the events.

\section{Discussion}

In the previous section we have presented observations of FACs and some other features during the strong geomagnetic storms of October and November 2003. During these storms the CHAMP satellite was orbiting the Earth close to the noon/midnight meridian. This orbit allows us to compare the features of the FACs on the dayside and nightside. Furthermore, the fact that the storms occur during or relatively close to the winter season offers us the opportunity to investigate the differences between sunlit and dark polar regions. To our knowledge, a detailed study of the storm-time FACs' characteristics has not yet been performed.

\subsection{Latitude variation}

During periods of enhanced solar wind input into the magnetosphere, the auroral oval expands equatorward, which may be associated with the expansion of the polar cap and indicate the pile-up of open flux (Milan et al., 2004). FACs can be regarded as a suitable marker for the mean latitude of the auroral oval. As shown in Figs. 4 and 8, the equatorward shift of the dayside FACs appears to be controlled directly by the southward IMF. To confirm this correlation we have plotted the FAC latitudes versus the IMF $B_{z}$ values. We have taken a 15-min delay of the IMF data into account for the response at the ionosphere to the development of the FACs from the magnetopause (Vennerstr $\phi \mathrm{m}$ et al., 2002). Figure 10 demonstrates a convincing linear correlation between the FACs and negative IMF $B_{z}$ for the November storm (bottom two panels), but the linear relationship is not as apparent due to a significant amount of scatter for the October storms (top two panels). Within each panel we have plotted a line resulting from the correlations obtained here. The slope of the lines represents the scaling factor used in Figs. 4 and 8, calculating the FAC latitude from the IMF $B_{z}$. It can be seen that the slopes of the lines are different for the October and November storms. For October the scaling factor (i.e. the slope of the line) is $0.9 \mathrm{deg} / \mathrm{nT}$ and for November it is $0.5 \mathrm{deg} / \mathrm{nT}$. From the significant difference in the slopes we can conclude that there must be other quantities which can also influence 
the FACs' equatorward expansion. In addition to IMF $B_{z}$, $P_{d}$ may be another parameter influencing the equatorward expansion, that is, the size of the polar cap. According to Boudouridis et al. (2003) and Milan et al. (2004), a high $P_{d}$ prevents the pile-up of magnetic flux in the lobes and thus impedes the expansion of the polar cap. During the November storm $P_{d}$ was higher than the third storm event of October. This observation may explain the reduced equatorward expansion of the FACs on the dayside during the November event. When compared to the November storm, the stronger response of the polar cap area to IMF $B_{z}$ for the October events may be due to the smaller $P_{d}$ (and thus less effective). Due to the uncertainty in $P_{d}$ for the October storms, we are unable to further investigate our hypothesis.

The bottom two panels in Fig. 10 also show that the latitudinal position of the dayside FACs saturates for large, negative $B_{z}$ values. The effect is also evident in the Northern Hemisphere for the October storms (upper left panel). In addition, we find that the saturation starts for smaller southward IMF in the Northern than in the Southern Hemisphere. The earlier saturation in the north may be due to the difference in solar illumination in the two hemispheres. Nagatsuma (2004) studied the dependence of the saturation of the cross polar cap potential on solar zenith angle and found that the saturation tends to start earlier for smaller solar zenith angles (i.e. under sunlit conditions). We hypothesize that this saturation due to solar illumination may also apply to the FACs' latitudinal extent. Unfortunately, he did not compare directly the saturation level in winter (dark polar cap) to that in summer (sunlit polar cap).

On the nightside the equatorward expansion of the FACs occur with some delay relative to the solar wind input. We have observed that the poleward retreat of the FACs is gradual during the recovery phase and the latitudinal motion of the equatorward boundary is more correlated with the variation of $D_{s t}$ than with $B_{z}$. This confirms the closer relation of the ring current intensity with the processes in the magnetospheric tail.

According to Cowley and Lockwood (1992), open magnetic flux is added to the polar cap by dayside reconnection, and after convecting tailward it is removed by reconnection in the tail. An increase in the magnetopause reconnection rate (e.g. due to strong southward IMF) results in the growth of the polar cap until a new equilibrium is obtained. We have observed an equatorward expansion of the dayside FACs that might reflect this growth of the polar cap, but we have noted that the equatorward expansion on the dayside is different in the two hemispheres. For both storm periods examined the maximum dayside equatorward expansion is displaced by about $5^{\circ}$ in latitude in the sunlit polar region. According to the reconnection theory, the amount of open flux has to be, however, the same in both tail lobes, thus northern and southern polar caps should have about the same size. The size of the polar cap, according to the model of Milan (2004), is determined by a balance between the reconnection processes at the magnetopause and in the tail. To solve this apparent conflict, we may keep in mind that the peak FAC location is a good indicator for the auroral oval on the dayside, but it does not mark the boundary of the polar cap clearly on the nightside. Auroral images and particle measurements would be needed to delineate the polar cap area. To keep the balance of open flux in both hemispheres, a larger equatorward displacement of the open/closed boundary on the dayside in the summer hemisphere needs to be compensated by a poleward shift of the polar cap boundary in other sectors, so that the area in both hemisphere is equal. Our results indicate a global asymmetric distribution of dayside FACs, which suggests a seasonally dependent displacement of the mean auroral oval during severe storms, but additional work is needed to confirm this point.

On the nightside the FAC pattern becomes more complicated, consisting of many pairs of upward and downward sheets, which cover a wide range of invariant latitudes. Similar observations have been made in the past (e.g. Fujii et al., 1992; Anderson et al., 2002; Ebihara et al., 2005). The multiple upward and downward sheets during the storm imply that tail reconnection takes place simultaneously at several distances from the Earth (Ma et al., 1995). During such periods, the simple concept of near-Earth current disruption (Lui, 1996) and the distant X-line (Baker et al., 1996) may no longer apply. Patches of plasma may be caught in detached flux ropes in the tail (Elphic et al., 1986). The downtail transport of these flux ropes may be impeded due to the multiple reconnection regions.

\subsection{Peak FAC intensity}

The FAC intensities determined during the extreme storms of this study are, on average, a factor of 5 larger than nominal FAC intensities (Wang et al., 2005). Furthermore, the FAC densities on the dayside are, on average, 2.5 times larger in the Southern (summer) than in the Northern (winter) Hemisphere. This observation is consistent with earlier studies by Fujii et al. (1981); Wang et al. (2005), who found that the FAC intensity on the dayside is dependent on the Suninduced ionospheric conductivity. The FAC intensity on the nightside is less dependent on solar illumination and is comparable in both hemispheres.

Table 1 lists the largest current densities encountered in each of the storms. Based on the values given in the table we believe that the dayside and nightside peak FAC densities are unrelated to each other. But even in the same time sector the peak current densities in opposite hemispheres are rarely observed during the same orbit. We believe that this is due to the seasonal dependence of the FACs densities.

For the largest FAC densities there is no simple relation with the solar wind input, characterized by the quantities IMF $B_{z}, E_{m}$ or the $\varepsilon$ parameter. However, as we have already alluded to, the dayside FACs' strength for the November storm is well correlated with $P_{d}$. Figure 11 shows the time series of solar wind input parameters $B_{z}$ (top panel) and $P_{d}$ (middle panel), as well as the integrated FAC for both hemispheres for the dayside sector of the November event. Both $B_{z}$ and $P_{d}$ are averages for the polar pass. These 

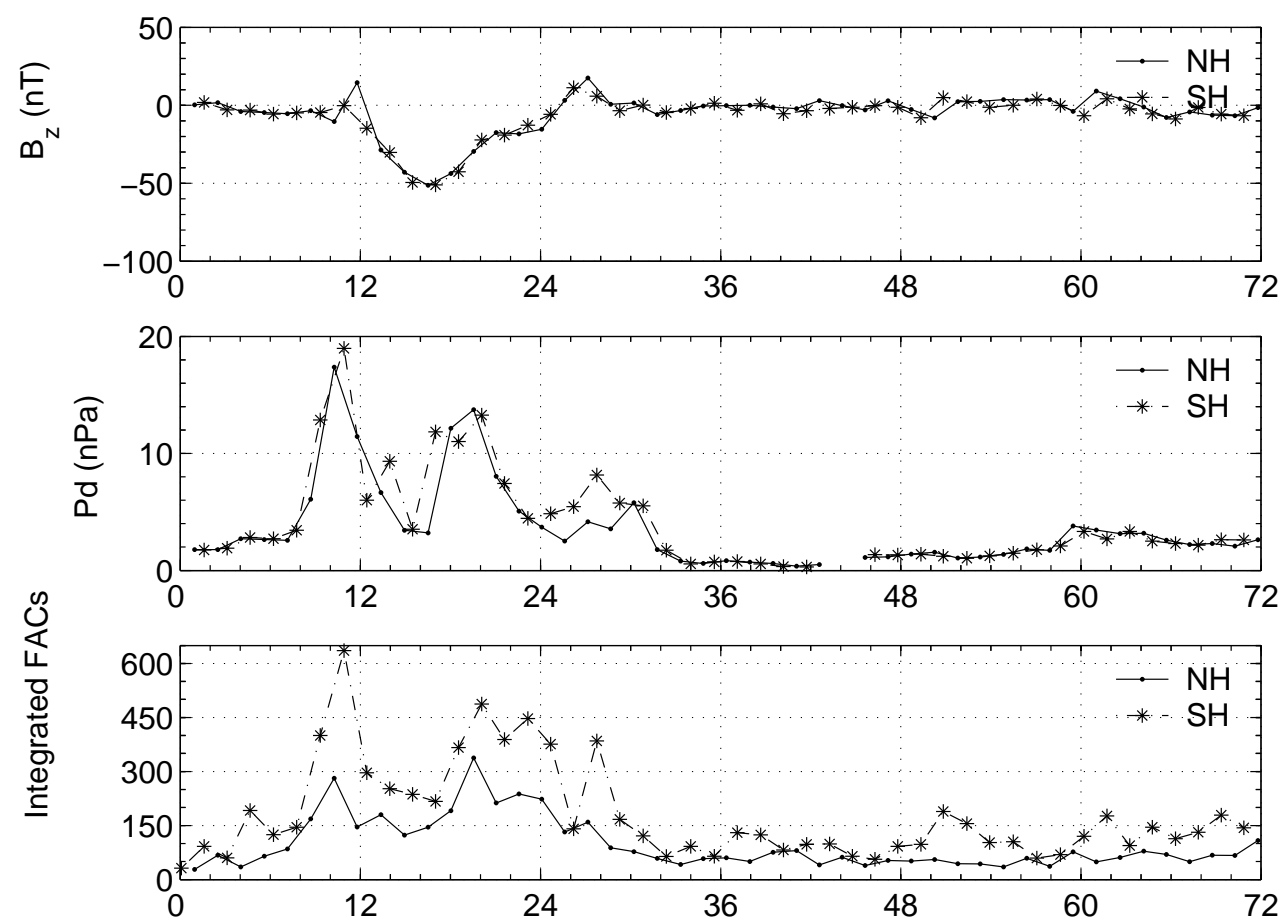

Fig. 11. Storm-time $B_{z}, P_{d}$ and integrated FACs' strength along the orbit segments $\left(\Sigma\left|j_{z}\right|\right)$ observed by CHAMP in the daytime sector on 20-22 November 2003 in the Northern and Southern Hemispheres.

values have been time delayed $15 \mathrm{~min}$ to account for the ionospheric response from the magnetosphere (Vennerstr $\phi \mathrm{m}$ et al., 2002). The time series of integrated FACs are determined by summing up the absolute FAC densities from a current-free location ( $40^{\circ}$ MLAT employed in this study) to the highest latitude of each crossing. The integration includes both the negative and positive FAC densities and thus represents the total FAC in each segment of the orbit. The top two panels of Fig. 11 demonstrate that there is little change in the solar wind input conditions between CHAMP's passages of the polar regions in the two hemispheres, which are separated by $\sim 30$ minutes. In the bottom panel of Fig. 11 there are two prominent peaks in the values of integrated FAC strength in both hemispheres. The first peak occurs around 10:00 ST and the second local maximum occurs around 20:00 ST. These maxima in the integrated FAC strength correlate with enhancements in $P_{d}$ that occur at approximately the same time. The correlation coefficient between the integrated FACs strength and $P_{d}$ is 0.82 for the Northern and 0.92 for the Southern Hemisphere, which supports our previous statement that $P_{d}$ is one of the main parameters controlling the strength of the FACs on the dayside. The increase in the FAC strength is not surprising. When a high $P_{d}$ enhancement compresses the magnetosphere, the magnetopause moves in towards the Earth. As a result, the current system (magnetopause current, tail current, as well as R1 field-aligned currents) increases in order to sustain the new location of the magnetopause (Boudouridis et al., 2003).
Another study that supports our findings is that of Shue and Kamide (2001). They found that sudden enhancements of $P_{d}$ had very different effects on the ionospheric electojets during northward or southward IMF. During southward IMF, the auroral electojets were strongly correlated with the solar wind density, while during northward IMF the correlation was weaker. Their findings are identical to what we have observed in the FAC during $P_{d}$ enhancements in the November extreme storm.

\section{Summary}

In this study, we have investigated the Northern and Southern Hemisphere FAC characteristics during the extreme October and November 2003 magnetic storms. We have identified a number of FAC characteristics during these storms.

First, we have determined that the equatorward motion of FACs on the dayside is, in general, correlated with the strength of the IMF southward component, but the minimum latitude of the FACs is limited to $52^{\circ}\left(56^{\circ}\right)$ in the Northern (Southern) Hemisphere for large negative values of $B_{z}$. The saturation is found to start at higher poleward latitudes in the Northern (winter) than in the Southern (summer) Hemisphere. Based on these observations we conclude that there is a seasonal asymmetry between the two auroral ovals during the main phase of an intense storm.

Second, we have observed a significant delay in the equatorward expansion of the nightside FACs relative to the 
solar wind IMF $B_{z}$ input. The latitudinal motion of the equatorward FACs in the nightside sector appears to be correlated with the variation of the $D_{s t}$ index. On the nightside there is a large latitudinal spread of strong FACs covering almost $25^{\circ}$. The poleward edge of the FACs remains between $75^{\circ}$ and $80^{\circ}$, while the equatorward edge expands away from the pole.

Furthermore, our observation shows that the FAC densities on the dayside are, on average, 2.5 times larger in the Southern (summer) than in the Northern Hemisphere. The dayside Southern Hemisphere current densities are larger due to the higher ionospheric conductivity caused by photoionization. On the nightside the observed FAC intensities are comparable between the two hemispheres.

Finally, during magnetic storms, $P_{d}$ seems to play an important role for the energy input into the ionosphere. For negative IMF $B_{z}$ there is a good correlation between the FAC intensity and $P_{d}$ variations. $P_{d}$ enhancements cause significant increases in the FAC strength on the dayside. A larger statistical study involving more magnetic storms is required to verify our results.

Acknowledgements. We thank the ACE MAG and SWEPAM instrument teams and the ACE Science Center for providing the ACE data. We thank the World Data Center C2, Kyoto, for providing the $D_{s t}$ data. H. Wang was supported by a Sandwich-type scholarship programme between China and Germany provide by the Deutsche Akademische Austauschdienst (DAAD). This study was supported by the China Ministry of Science and Technology (No. G2000078407) and National Nature Science Foundation of China (No. 40390150). We gratefully acknowledge the operational support of the CHAMP mission, which was provided by the German Aerospace Center (DLR), and the financial support for the data processing, which was provided by the Federal Ministry of Education and Research (BMBF), as part of the Geotechnology Programme.

Topical Editor T. Pulkkinen thanks A. Viljanen and another referee for their help in evaluating this paper.

\section{References}

Akasofu, S. I.: Interplanetary energy flux associated with magnetospheric substorms, Planet. Space. Sci., 27, 425-431, 1979.

Anderson, B. J., Takahashi, K., Kamei, T., Waters, C. L., and Toth, B. A.: Birkeland current system key parameters derived from Iridium observations: Method and initial validation results, J. Geophys. Res., 107, doi:10.1029/2001JA000080, 2002.

Baker, D. N., Pulkkinen, T. I., Angelopoulos, V., Baumjohann, W., and McPherron, R. L.: Neutral line model of substorms: Past results and present view, J. Geophys. Res., 101, 12 975-13 010, 1996.

Boudouridis, A., Zesta, E., and Lyons, L. R.: Effect of solar wind pressure pulses on the size and strength of the auroral oval, J. Geophys. Res., 108, doi:10.1029/2002JA009373, 2003.

Burch, J. L.: Effects of the interplanetary magnetic field on the auroral oval and plasmapause, Space Science Review, 23, 449-455, 1979.

Bythrow, P. F., Potemra, T. A., and Zanetti, L. J.: Variation of the auroral Birkeland current pattern associated with the north-south component of the IMF, in: Magnetospheric Currents, GM. 28, AGU, Washington D.C., 131-136, 1984.
Christiansen, F. and Papitashvili, V. O.: Storm time field-aligned currents detected by the Ørsted and champ satellites, in: OIST-4 Proceedings, edited by: Stauning, P., 1-3, DMI Press, Copenhagen, 2003

Cowley, S. W. H. and Lockwood, M.: Excitation and decay of solarwind-driven flows in the magnetosphere-ionosphere system, Ann. Geophys., 10, 103-115, 1992.

Ebihara, Y., Fok, M. C., Sazykin, S., Thomsen, M. F., Hairston, M. R., Evans, D. S., Rich, F. J., and Ejiri, M.: Ring current and the magnetosphere-ionosphere coupling during the super storm of 20 November 2003, J. Geophys. Res., 110, doi:10.1029/2004JA010924, 2005.

Elphic, R. C., Cattell, C. A., Takahashi, K., Bame, S. J., and Russell, C. T.: ISEE-1 and 2 observations of magnetic flux ropes in the magnetotail: FTE's in the plasma sheet?, Geophys. Res. Lett., 13, 648-651, 1986

Friis-Christensen, E. and Wilhjelm, J.: Polar cap currents for different directions of the interplanetary magnetic field in the $y-z$ plane, J. Geophys. Res., 80, 1249-1260, 1975.

Fujii, R., Iijima, T., Potemra, T. A., and Sugiura, M.: Seasonal dependence of large-scale Birkeland currents, Geophys. Res. Lett., 8, 1103-1106, 1981.

Fujii, R., Fukunishi, H., Kokubun, S., Sugiura, M., Tohyama, F., Hayakawa, H., Tsyryda, K., and Okada, T.: Field-aligned currents signatures during the March 13-14, 1989, great magnetic storm, J. Geophys. Res., 97, 10 703-10 715, 1992.

Gonzalez, W. D. and Tsurutani, B. T.: Criteria of interplanetary parameters causing intense magnetic storms (Dst $<-100 \mathrm{nT}$ ), Space Sci., 35, 1101-1109, 1987.

Gopalswamy, N., Barbieri, L., Lu, G., Plunkett, S. P., and Skoug, R. M.: Introduction to the special section: Violent Sun-Earth connection events of October-November 2003, Geophys. Res. Lett., 32, doi:10.1029/2005GL022348, 2005a.

Gopalswamy, N., Yashiro, S., Michalek, G., Xie, H., Lepping, R. P., and Howard, R. A.: Solar source of the largest geomagnetic storm of cycle 23, Geophys. Res. Lett., 32, doi:10.1029/2004GL021639, 2005b.

Iijima, T. and Potemra, T.: Field-aligned currents in the dayside cusp observed by Triad, J. Geophys. Res., 81, 5971-5979, 1976.

Iijima, T. and Potemra, T.: The amplitude distribution of fieldaligned currents associated with substorms, J. Geophys. Res., 83, 599-615, 1978.

Lühr, H., Warnecke, J., and Rother, M. K. A.: An algorithm for estimating field-aligned currents from single spacecraft magnetic field measurements: A diagnostic tool applied to Freja satellite data, Geosci. Remote Sens., 34, 1369-1376, 1996.

Liu, H. and Lühr, H.: Strong disturbance of the upper thermosphere density due to the magnetic storms: CHAMP observations, J. Geophys. Res., 110, doi:10.1029/2004JA010908, 2005.

Lui, A. T. Y.: Current disruption in the Earth's magnetosphere: Observations and models, J. Geophys. Res., 101, 13 067-13 088, 1996.

Ma, Z. W., Lee, L. C., and Otto, A.: Generation of field-aligned currents and Alfvén waves by 3D magentic reconnection, Geophys. Res. Lett., 22, 1737-1740, 1995.

Maltsev, Y. P.: Points of controversy in the study of magnetic storms, Space Science Review, 110, 227-277, 2004.

Mauk, B. H. and Zanetti, L. J.: Magnetospheric electric fields and currents, Rev. Geophys., 25, 541-554, 1987.

Meng, C. I.: Dynamic Variation of the Auroral Oval During Intense Magnetic Storms, J. Geophys. Res., 89, 227-235, 1984.

Milan, S. E.: A simple model of the flux content of the distant 
magnetotail, J. Geophys. Res., 109, doi:10.1029/2003JA010350, 2004.

Milan, S. E., Cowley, W. H., Lester, M., Wright, D. M., Slavin, J. A., Fillingim, M., Carlson, C. W., and Singer, H. J.: Response of the magnetotail to changes in the open flux content of the magnetosphere, J. Geophys. Res., 109, doi:10.1029/2003JA010350, 2004.

Nagatsuma, T.: Conductivity dependence of cross-polar potential saturation, J. Geophys. Res., 109, doi:10.1029/2003JA010 286, 2004.

Reigber, C., Lühr, H., and Schwintzer, P.: CHAMP mission status, Adv. Space Res., 30, 129-134, 2002.

Richmond, A. D.: Ionospheric Electrodynamics Using Magnetic Apex Coordinates, J. Geomagn. Geoelectr., 47, 191-212, 1995.

Shue, J. H. and Kamide, Y.: Effects of solar wind density on auroral electrojets, Geophys. Res. Lett., 28, 2181-2184, 2001.

Siscoe, G. L., Erickson, G. M., Sonnerup, B. U. Ö., Maynard, N. C., Schoendorf, J. A., Siebert, K. D., Weimer, D. R., White, W. W., and Wilson, G. R.: Hill model of transpolar potential saturation: Comparisons with MHD simulations, J. Geophys. Res., 107, doi: 10.1029/2001JA000109, 2002.

Skoug, R. M., Steinberg, J. T., McComas, D. J., and Smith, C. W.: Extremely high speed solar wind: 29-30 October 2003, J. Geophys. Res., 109, doi:10.1029/2004JA010494, 2004.

Sugiura, M. and Potemra, T. A.: Net field-alinged currents observed by Triad, J. Geophys. Res., 81, 2155-2164, 1976.
Troshichev, O. A. and Lukianova, R. Y.: Polar cap index (PC) as a proxy for ionospheric electric field in the near-pole region, Geophys. Res. Lett., 27, 3809-3812, 1996.

Vennerstr $\phi \mathrm{m}$, S., Moretto, T., Olsen, N., Friis-Christensen, E., Stampe, A. M., and Watermann, J.: Field-aligned currents in the dayside cusp and polar cap region during northward IMF, J. Geophys. Res., 107, doi:10.1029/2001JA009162, 2002.

Wang, H., Lühr, H., and Ma, S. Y.: Solar zenith angle and merging electric field control of field-aligned currents: A statistical study of the southern hemisphere, J. Geophys. Res., 110, doi:10.1029/2004JA010530, 2005.

Weimer, D. R., Ober, D. M., Maynard, N. C., Collier, M. R., McComas, D. J., Ness, N. F., Smith, C. W., and Watermann, J.: Predicting interplanetary magnetic field (IMF) propagation delay times using the minimum variance technique, J. Geophys. Res., 108, doi: 10.1029/2002JA009405, 2003.

Yizengaw, E., Moldwin, M. B., Dyson, P. L., and Immel, T. J.: Southern Hemisphere ionosphere and plasmasphere response to the interplanetray shock event of 29-30 October 2003, J. Geophys. Res., 110, doi:10.1029/2004JA010920, 2005.

Zanetti, L. J., Baumjohann, W., and Potemra, T. A.: Ionospheric and Birkeland Current Distributions Inferred from the Magsat Magnetometer Data, J. Geophys. Res., 88, 4875-4884, 1983. 